\title{
MITI and STA avoid squeeze on spending
}

Tokyo Japan's Ministry of Finance has taken advantage of the recent change of government to try to clamp down on spending on science next fiscal year. But the Ministry of International Trade and Industry (MITI) and the Science and Technology Agency (STA) have avoided the squeeze and include significant new appropriations in their budget requests for 1994 submitted on Tuesday, 31 August.

Days after the new Prime Minister Morihiro Hosokawa took power, the Ministry of Finance insisted that a new category of budget established last year by the former ruling Liberal Democratic Party (LDP) to support academic research should be abolished. The demise of the LDP gave the ministry the opportunity to make this move.

The new fund in theory added $¥ 110$ billion (about $\$ 1$ billion) to the budgets of all science-related ministries and agencies. In practice, it merely reduced the amount by which the budget for general operating expenditures must decrease each year under a policy of fiscal restraint (see Nature 358, 530; 1993). Nevertheless, it did give the science-related ministries and agencies room to win some of the biggest increases in their their overall budgets in many years.

Abolition of the fund has been a "very big disadvantage" in budget negotiations, says Tadatsuna Koda, director general of the general coordination department of the Agency of Industrial Science and Technology (AIST), MITI's main research arm. AIST's budget request for its general account increases by only 2.7 per cent, compared with a 4.6 per cent increase this fiscal year, and this request will be trimmed in negotiations with the finance ministry before the budget is finalized at the end of December.

MITI is getting around the squeeze by boosting a separate special account derived from taxes on fossil fuels and electricity. With a large increase in this account, MITI hopes to get an overall increase of 7.5 per cent in its research and development budget to $¥ 302$ billion ( $\$ 2.9$ billion). Most of the extra money is going into projects related to development of environment friendly technology, such as the 'New Sunshine Programme' and the Research Institute of Innovative Technology for the Earth (RITE).

The STA, which is requesting an increase of 6.1 per cent to $¥ 617$ billion, has also avoided the worst of the squeeze because a large portion of its budget, for example for space and nuclear power, is classified as "investment" and can be increase by 5 per cent under Ministry of Finance rules. Furthermore, STA's commitments to international projects such as

the US Space Station and the International Thermonuclear Experimental Reactor are not subject to such severe budget restrictions.

A key component of STA's budget is a request for $¥ 1.1$ billion to establish an inter-ministry backbone computer network linking national research institutes and universities (see Nature 363, 575; 1993). The backbone running from Tsukuba science city through Tokyo to the Osaka - Kyoto area will have a capacity of 6 megabits-per-second, more than 10 times the capacity of existing lines, and will link $40-50$ national institutes of

\section{Science jamboree in transition}

Keele.The British Association for the Advancement of Science (BA) seems to be having a good annual meeting this year, even though holed up and isolated on this 1960 s campus, a grand country house whose surrounding park has been half-filled with teaching blocks and student dormitories in an architectural style that, except for a few touches of new brutalism, is a monument to an earlier age of optimism.

The annual meeting, trendily renamed a "science festival", used to be the BA's sole activity and only contact with its members. Now it has an annual budget of $£ 1$ million (mostly from grants and commissions), and has embarked on novel ventures such as a meeting earlier this year intended (now altogether successfully) to confront financial institutions of the City of London with scientists' complaints that short-term money calculations are the death of innovation.

The most important ingredient in the BA's budget is a government grant of $£ 140,000$ (this year), laundered through the Royal Society; without that, other grants (notably $£ 50,000$ a year from the Wellcome Trust) would be raised only with greater difficulty. But Peter Briggs, a more hard-headed secretary than the BA has had for decades, recognizes that the organization needs more paying members; there are only 1,700 at present, of whom a large number bought life memberships at earlier bargain prices.

The association, earlier this week, was also looking for some tangible further encouragement when $\mathrm{Mr}$ William Waldegrave, the government minister with responsibility for science and technology, who would appear at Keele later in the week. (This visit by a science minister to the BA's annual meeting is unprecedented, but so, apart from a brief spell in the early 1960s, is Waldegrave's post.) numerous ministries and agencies, including even one of the Ministry of finance and another of the Police Agency. The backbone will also be connected to the SINET backbone that links universities run by the Ministry of Education, Science and Culture and to the 45 megabit network of the National Science Foundation in the United States.

STA also requests a doubling in its budget for 'centres of excellence' from $¥ 1.2$ billion to $¥ 2.4$ billion to allow three more centres to be chosen next year (see Nature 364, 660; 1993).

David Swinbanks

The annual meeting has been modestly transformed from the pattern of the distant past. This year as for some past, the occasion has been used by organizations other than the BA's own specialized section to present symposia, to the benefit of all. Thus Keele is the occasion of the Fifth European Skeptics' Conference (that of the people who have no time for the paranormal except for what they spend denouncing it), a visionary look forward organized by the Royal Society's Committee on the Public Understanding of Science and a similar exercise in the field of health organized by Glaxo, the pharmaceutical manufacturer.

Yet the oddly miscellaneous character of the programme persists, with the case for hydrogen as a road transport fuel (Professor James Randle, University of Birmingham), the conservation of tropical rain forests (a chorus of speakers), the continuing shortage of specialist teachers in British schools (Professor Alan Smithers, University of Manchester) and the case for regarding financial speculators as moral agents of the financial system rather than as immoral parasites on it (Sir Samuel Brittan, Financial Times). The last will be supported by an ex-chancellor of the exchequer, Lord Lawson, later in the week.

As always, to judge from a small sample earlier this week, individual presentations tend to overstray the allotted time, leaving too little for discussion. And such as there is tends to be muted by diffidence and gentility. That may be another reason for applauding the BA's ambition to concentrate, in the future, on taking its annual message to the big cities, where there will be more day visitors (who will also contribute to the association's funds). It seems, as always, a pity that so much scholarly entertainment should be so confined.

John Maddox 